\title{
Manual de Boas Práticas para Cadastro de IP
}

Nos últimos meses o CPI (Centro Português de Iluminação) tem realizado uma série de seminários, por todo o País, para divulgar o seu último documento, recentemente impresso, "Manual de Boas práticas para Cadastro de IP".

É pertinente perguntar porque é que havendo iluminação pública há mais de 100 anos em Portugal, se lembra agora o CPI da criação de um " Manual de Boas práticas para Cadastro de IP".

As razões para a criação de um documento sobre um tema aparentemente fácil e óbvio são muitas, como veremos mais adiante.

A crise económica que abraçou o país a partir de 2010 demonstrou que as opções políticas energéticas em Iluminação Pública (IP) não são sustentáveis face aos custos operacionais inerentes.

Neste sentido, e nesse mesmo ano, a Secretaria de Estado de Economia e Energia convidou-me para integrar um grupo de trabalho para a criação do Documento de Referência para a Eficiência Energética na Iluminação Pública (DREEIP) com intuito de dotar os Municípios/Decisores de um instrumento que aponte para soluções sustentáveis do ponto de vista de eficiência energética na iluminação, independentemente da fonte ou da tecnologia utilizada.

Apesar de estar em vigor a portaria 454 de Maio de 2001 que no seu anexo 1 define níveis e uniformidade a projetar nas vias, a verdade é que as tecnologias, as tendências de projeto evoluíram, a maneira como encaramos o espaço urbano também, os utilizadores estão mais sensíveis à qualidade e eficiência de iluminação e a crise económica obriga-nos a repensar todo o sistema.

Terminado o DREEIP coube-me a mim a divulgação dos objetivos do mesmo, contando para o efeito com o apoio da RNAE e de vários Municípios.
No decurso destas conferências tive a oportunidade de contactar de perto com muitas entidades e ESE's que direta ou indiretamente, estavam à procura de soluções sustentáveis para sistemas de iluminação pública (IP).

Estes agentes em coordenação com as entidades responsáveis pela gestão dos sistemas de lluminação Pública procuravam recorrer a mecanismos de financiamento que Ihes permitissem implementar algumas medidas de eficiência energética que visassem conduzir à redução de consumos energéticos na lluminação Pública.

Os contactos permitiram verificar que, na maioria das situações, esses financiamentos quando avançaram foram afetos a investimentos avulsos ou em vias de, sem que as entidades gestoras efetuassem uma prévia avaliação do estado de conservação e operacional dos sistemas de Iluminação Pública, por forma a poderem descortinar quais as situações a corrigir e canalizar os investimentos para métodos e tecnologia de uma forma mais assertiva.

Algumas dessas entidades apresentavam, no decurso destas conferências, casos práticos de cadastros de IP pouco esclarecedores, para todos os gostos e feitios, quase todos sem atualização, portanto radiografias, com no e tipos de atributos diferentes, mais ou menos precisos, não integrados num SIG, nalguns casos sem potência das lâmpadas, identificação dos modelos, estado de conservação dos equipamentos de IP, georreferenciados em alguns casos com recurso a GPS de navegação e não de aquisição, manejados por pessoas sem experiência e nalguns casos com equipas sem a presença de eletrotécnicos e de geógrafos.

Outros utilizavam o cadastro fornecido pela concessionária que, no meu entender, pode ser complementar mas não é suficiente como base para quem tem de gerir e decidir sobre um espaço urbano, pois este cadastro é realizado pela concessionária com atributos adaptados às suas necessidades de gestão de rede. 
Constatei também que muitas das pessoas que andavam no terreno me punham questões que revelavam um grande desconhecimento do sistema de IP, nomeadamente geógrafos que me davam a conhecer a sua dificuldade em caracterizar o sistema elétrico de IP, o que é perfeitamente normal dada a sua especialidade e à necessidade de haver equipas multidisciplinares no terreno.

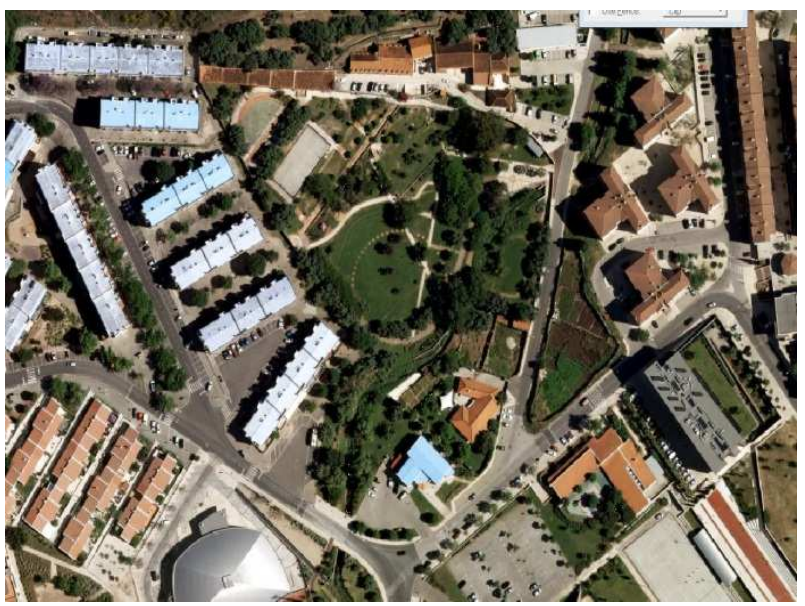

Figura 1. Exemplo de excerto de um ortofotomapa de grande resolução

Por outro lado, é bom lembrar que a maioria dos contratos de concessão acabam entre 2015 e 2021 e é necessário que as autarquias tenham o sistema de IP cadastrado para uma possível negociação em futuras concessões.

Resumindo, não sabemos quantos pontos de luz temos em Portugal, nem quanto ao tipo, funcional ou decorativa, potência, estado real de conservação, nem quanto à justificação da potência, localização ou até à própria necessidade de existirem em alguns locais.

Em muitos casos não sabemos o que está ligado à IP, como outdoors, cabines telefónicas, paragens de autocarro, etc. Foram-se ligando, ao abrigo de protocolos, mas não se registaram ou atualizaram.

Há circuitos IP ligados a armários de BT e sem contagem, há circuitos que englobam pontos de luz de dois municípios ou entidades diferentes embora a contagem pertença apenas a um deles.
Os cadastros que existem são insuficientes para um correto planeamento de um sistema IP eficiente e para planearmos, precisamos de conhecer o que existe, como existe e o porquê da sua existência.

Para que as entidades gestoras estejam municiadas de informação sobre o estado do seu sistema de IP é fundamental a existência de um Cadastro de Iluminação Pública, bem como a implementação de medidas e práticas que conduzam à sua permanente atualização, caso contrário - cadastro perderá toda a sua potencialidade como ferramenta base de gestão. A necessidade de uma atualização constante e articulada com todos os intervenientes no sistema deverá ser um procedimento a adotar entre as partes.

É neste sentido que o CPI sentiu a necessidade da elaboração deste documento, de modo a criar um Manual de Referência para as boas práticas a adotar na implementação de um Cadastro de Iluminação Pública.

Este documento tem como metas ajudar as entidades gestoras e demais atores neste processo na elaboração do Cadastro da lluminação Pública, explicitando as metodologias e modelos de dados (organização, classes de objetos e atributos) que deverão ser contemplados.

Apenas com um cadastro da lluminação Pública de qualidade e integrado será possível tomar medidas de gestão conscientes e conducentes a uma efetiva eficiência energética na lluminação Pública.

Falando agora do manual, o CPI considera que a implementação de um Cadastro de Iluminação Pública deve obedecer aos seguintes objetivos:

- Ser uma fonte de informação credível e rigorosa;

- Dar a conhecer a infraestrutura a todos os níveis de operacionalidade; 


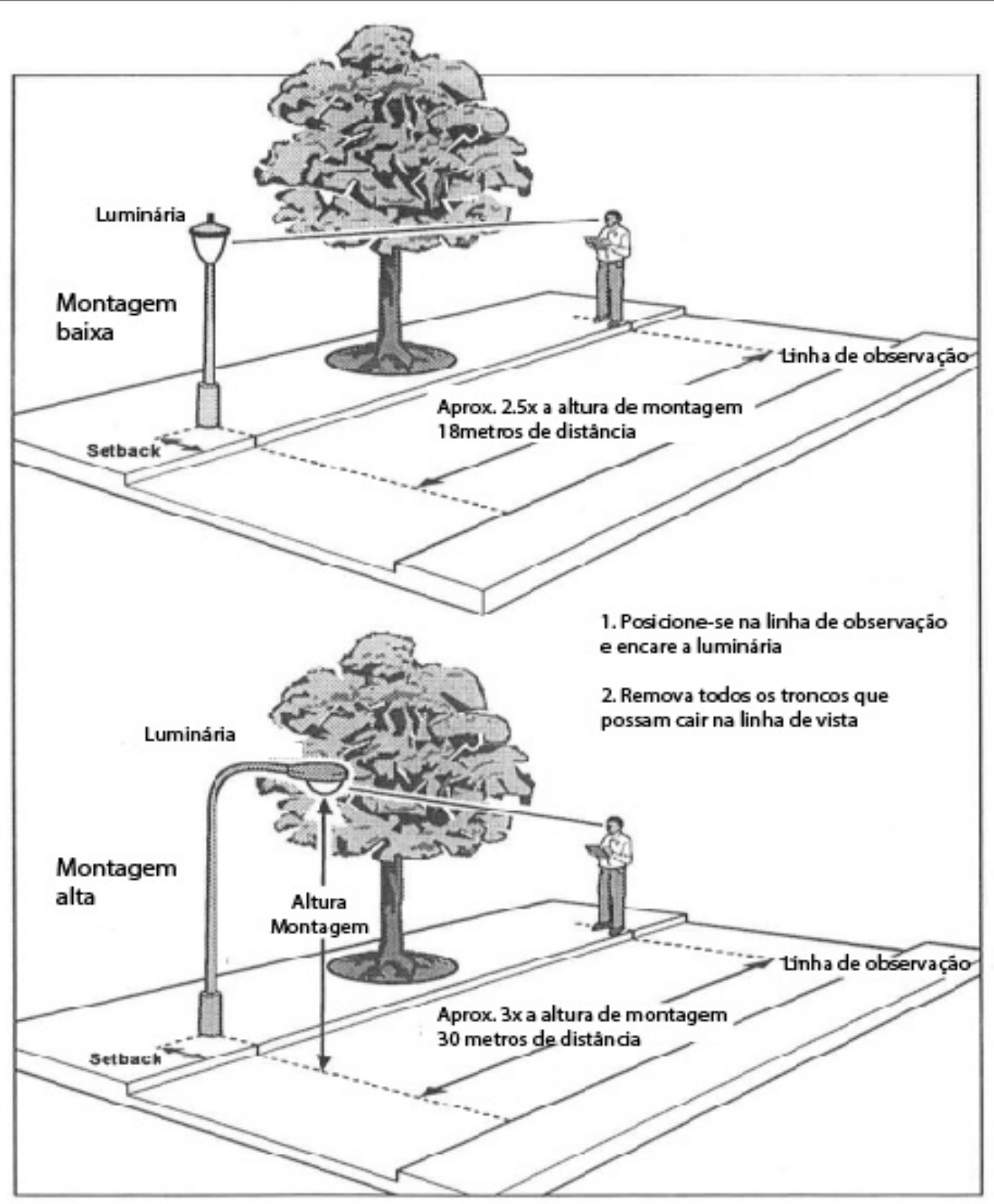

Pruning guide for trees located near strэet lights. For any mounting height (MH), the pruning height $(\mathbf{P H})$ at distance (D) from the luminaire pole may be calculated from: $\mathbf{P H}=(4 \mathrm{MH}-\mathrm{D}) / 4$.

Figura 2. Exemplo de obstrução, que deve ser registado no cadastro.

- Constituir-se como um suporte de dados e ferramenta de informação para diversas atividades que dependem de um cadastro rigoroso, nomeadamente:

- Planeamento e projeto;

- Análise e diagnóstico;

- Monitorização e avaliação de desempenho;

- Planeamento e ordenamento de território;

- Constituir-se como uma ferramenta para a gestão integrada dos sistemas de IP.
Para atingir tais objetivos, é importante interiorizar que um cadastro de IP tem que ter não só atividades de georreferenciação, como comumente é assumido, mas também de inventariação, numeração, identificação de elementos da rede e respetivas características técnicas, incluindo aspetos construtivos e de instalação, estado de conservação, modo de ligação, comportamento 
Deste modo, a realização de um cadastro técnico de Iluminação pública terá que passar por quatro componentes fundamentais, que são:

\section{Caracterização técnica}

- Caracterização da designação dos equipamentos e aparelhos - que inclui referências aos modelos, marcas, tipos, fabricantes, etc...

- Caracterização física dos equipamentos - que inclui formas, materiais, alturas, comprimentos, dimensões, etc...

- Caracterização de parâmetros energéticos associados aos equipamentos e instalações - que inclui potências, correntes, luminâncias, cor da luz, etc...

\section{Caracterização construtiva e de funcionamento}

- Caracterização do modo de instalação da rede - que inclui aspetos de natureza civil como assentamento/fixação dos apoios, o tipo de instalação dos circuitos (aéreos, subterrâneos,...), as características construtivas das instalações,...

- Caracterização do modo de estruturação da rede - que inclui a identificação dos circuitos e sua extensão, as características elétricas (potencias, correntes e outros parâmetros),...

- Caracterização do modo de ligação da rede - que inclui a criação de parâmetros de relação entre os circuitos as instalações e os Pontos de luz,...

-Caracterização da função das entidades em relação ao espaço e o meio envolvente - que inclui as características associadas com a conjugação e interação com o meio (vias, zonas, caracterização funcional)...

\section{Caracterização do estado de conservação}

- Caracterização de aspetos relacionados com manutenção dos equipamentos e infraestruturas de rede - que inclui danos nos equipamentos, desgastes, obstrução,...

\section{Georreferenciação}

Posicionamento rigoroso dos elementos e equipamentos de rede, bem como todos os elementos que interagem com os sistemas de iluminação pública - que inclui a georreferenciação das instalações, pontos de luz, vias, limites de zonas..

Essas 4 componentes derivam de duas atividades fundamentais para a realização de um cadastro:

- Levantamentos de Campo

- Tratamento de dados

Uma vez concluído o trabalho de execução de cadastro, e para ser possível gerir adequadamente a lluminação Pública, poderão ainda ser consideradas mais duas fases complementares:

Fase 1 - Integração de informação proveniente de outros sistemas, nomeadamente:

- Faturação e consumos registados;

- Sistemas automáticos de monitorização/medição implementados nas instalações: medições de parâmetros lumínicos, energéticos e do meio ambiental;

- Contratos associados à conservação e manutenção;

- Condições de segurança da rede.

\section{Fase 2 - Análise e diagnóstico da situação atual}

- Cruzamento da informação recolhida com a legislação vigente aplicável ao país em matéria de iluminação exterior, ou outra aceitável;

- Análise cruzada com outra informação integrada;

- Estudos de diagnóstico do sistema de IP.

Para um correto levantamento de campo, o CPI no seu manual define quais os atributos que deve ter uma equipa técnica e as características dos equipamentos que servirão de suporte a todo o levantamento de campo: 


\section{Equipa técnica}

Recomenda-se que as equipas que realizam os trabalhos de levantamento cadastral sejam multidisciplinares, capazes de reconhecer com facilidade os elementos da rede de lluminação Pública e as diversas tipologias de equipamentos.

Essas equipas devem ter sensibilidade para o modo de funcionamento da rede elétrica, conhecimento das características elétricas e capacidade de manusear os diversos tipos de equipamentos de medição. Devem igualmente ser capazes de interpretar os resultados das medições, por forma a assegurar a fiabilidade dos dados recolhidos e oferecer a garantia de qualidade da informação cadastral.

Os elementos das equipas devem ser detentores de formação de base em segurança e riscos inerente a toda a atividade a desenvolver, para não colocarem em causa a sua integridade física e da instalação / sistema de Iluminação Pública, bem como a de terceiros.

Os levantamentos que impliquem medições e manobras em PT e armários deverão ser realizados por técnicos devidamente habilitados para trabalhos em tensão. Deverão estar igualmente munidos de equipamentos de proteção individual (EPI).

\section{Equipamentos}

Para a realização dos trabalhos inerentes às atividades de tratamento de dados deverão ser disponibilizados os equipamentos e outros recursos informáticos compatíveis com os sistemas a utilizar, nomeadamente versões de software, capacidade de armazenamento de dados e ligações de rede sempre tal se justifique.

Nos equipamentos o manual subdivide duas categorias:

\section{1 - Instrumentos de Georreferenciação e medidas de distâncias}

Os recursos e meios a utilizar para a georreferenciação das entidades podem ser vários, sendo que estes deverão garantir as precisões que geralmente estão associadas a cadastro de infraestruturas, que de uma forma genérica se enquadram nas escalas planimétricas entre 1:1000 e 1:2000 e cujas precisões recomendadas se situam nos $30 \mathrm{~cm}$.

São sugeridos os seguintes instrumentos:

$1-$ GPS

2- Estação Topográfica Total

3- Base cartográfica existente

4- Distanciómetros

\section{2- Instrumentos de medida de parâmetros elétricos e} lumínicos

Para obter valores reais em detrimento de valores por estimativa devem ser utilizados equipamentos de medição de parâmetros elétricos e lumínicos. Estes equipamentos deverão ser selecionados tendo em conta a sua adequação aos trabalhos a realizar e devem estar nas devidas condições de utilização e calibração nos termos das Normais Nacionais.

Neste contexto, os equipamentos fundamentais para a operacionalização dos trabalhos de aquisição de dados durante a atividade de campo serão:

1 - Multímetro;

2- Luxímetro;

Como base de suporte às equipas responsáveis pela realização do cadastro o manual define uma série de entidades mínimas, etapas para o levantamento das mesmas, anexos que incluem registos fotográficos dos objetos a cadastrar, de modo a ajudar à caracterização e identificação dos mesmos e o anexo 5, que é uma ficheiro Excel que serve de suporte ao levantamento no terreno e que deve ser descarregado do site do CPI: www.cpi-luz.pt.

Finalmente, para se ter um cadastro atualizado e para que o mesmo constitua uma ferramenta fundamental e credível para as entidades gestoras de um sistema IP, o CPI considera que é necessária a criação de um gestor do sistema que fará a ponte com o concessionário, outros departamentos envolvidos na gestão do espaço urbano, equipas projetistas, etc. 
Entende-se que para desempenhar esse papel a qualificação mais óbvia será a de alguém com grandes conhecimentos de eletrotecnia e luminotecnia mais concretamente um engenheiro eletrotécnico.

O CPI considera que um cadastro desenvolvido de acordo com o Manual permitirá:

- Um conhecimento aprofundado de toda a infraestrutura

- Diagnosticar e avaliar todo o sistema de IP

- Ter uma base de desenvolvimento para um plano diretor de IP

- Facilitar a introdução de sistemas inteligentes de gestão de IP

- Fazer com que a iluminação pública possa constituir um instrumento de desenvolvimento, conforto, segurança e atratividade de uma área, de uma cidade, ou de uma região, ao mesmo tempo que potencia a perceção ambiental e influencia o comportamento humano, de um modo eficiente.
O manual está à venda em versão impressa e pode ser encomendado através do site do CPI com um preço para sócios e outro para não sócios, incluindo já ambos despesas de envio.

Fizeram parte do grupo de trabalho que criou este manual os seguintes elementos: Alberto Van Zeller, Vice-presidente do CPI e coordenador do grupo; os geógrafos Hugo Jorge, Sandra Cunha e João Melo, António Gomes, da Divisão de IP da CM de Lisboa; Paulo Nogueira, da Adene; e José Carlos Teixeira, Professor Universitário e especialista em sistemas de integração e avaliação.
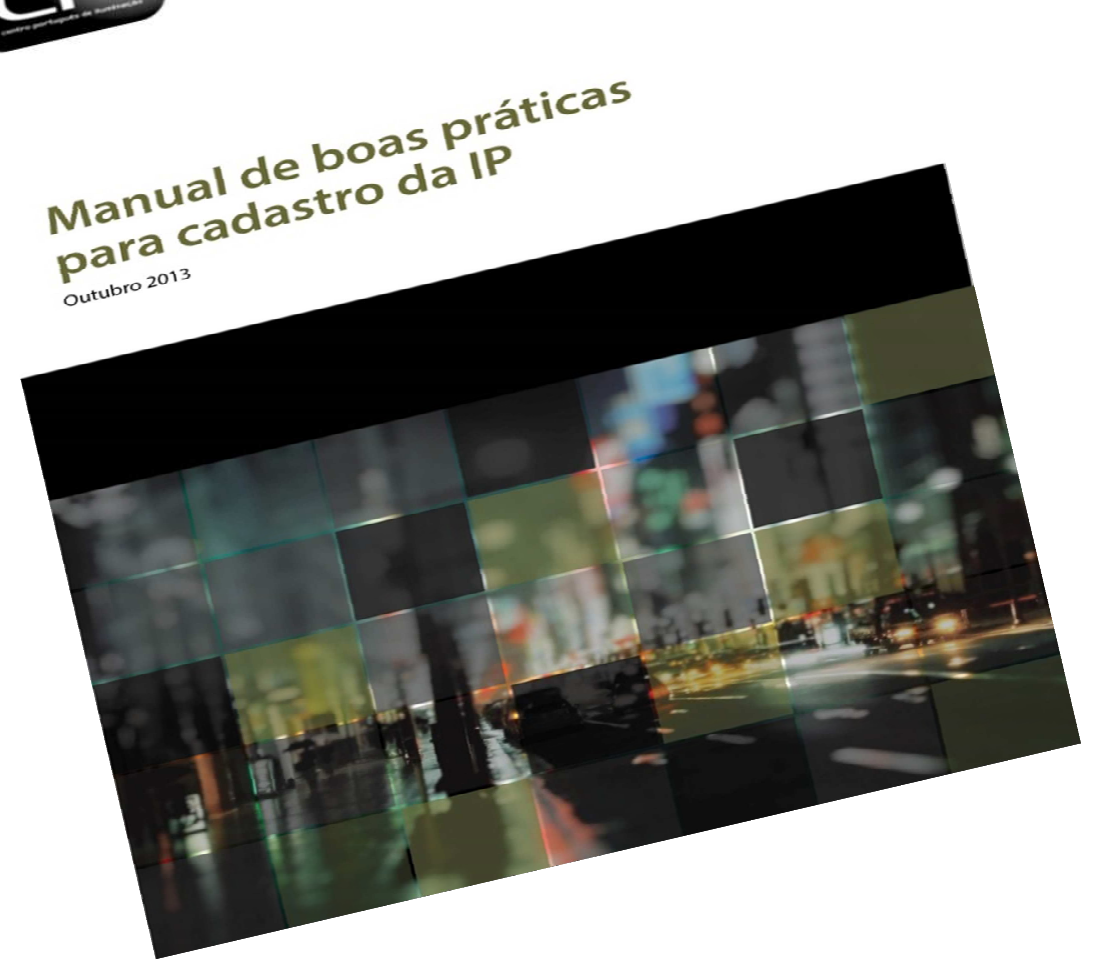